\title{
Positive Effects of Yoga in Control of Mental Distress (Illnesses)
}

\author{
Sanjay Kumar Gupta* \\ Infection Prevention and Control Department, AlRass General Hospital, Saudi Arabia
}

Submission: January 25, 2018; Published: June 26, 2018

*Corresponding author: Sanjay Kumar Gupta, Medical Coordinator Infection Prevention and Control Department AlRass General Hospital, Qassim, Saudi Arabia, Tel: +966 553618341; Email: sanjaygupta2020@gmail.com

\section{Introduction}

Yoga word derived from the Sanskrit word 'Yuj' or union, it is a very old discipline around 3000 year-old, that was developed as part of traditional Indian medicine for promotion of good health. It is the important tool for exploring the depth of human nature or examining the complexities of the body and mind. Yoga is now recognized as a one of the form of mind-body medicine, because it promotes the integration of physical, mental and spiritual parts, and because there is many scientific researches are also available to support its health benefits on human body. Yoga practice usually includes the use of physical postures, controlled breathing and meditation to improve overall wellbeing of the person or human body. Physical postures perform during yoga known as asanas, its provide the gentle workout that improves muscle strength, flexibility and body alignment and enhances circulation as well as hormone functions of the body . During yoga many breathing exercise is performed by person known as pranayama, means controlled inhalation, exhalation and retention of breath; it provides an adequate intake of oxygen to the body and an optimal removal of harmful gases such as carbon dioxide from the body.

In yogic philosophy centre on, there are seven energy centers in the body of human being called chakras, these chakras are located along the spinal column and correspond to the seven nerve plexuses in the human body. Mooladhara chakra is related to sexual function (sacral plexus) is situated at the root of the spinal cord between the genital organs and the anus and its regulates the various functions of sex glands and kidneys. Swadhisthana chakra related to bowel habits (lumbar plexus) is situated about four inches below the navel and its regulates the functions of colon and rectum. Manipura chakra related to digestive system, (coeliac plexus) is situated the level of the navel and regulates the functions of adrenal glands, stomach and intestines. Anahata chakra (cardiac plexus) is situated at the level of the heart and regulates the functions of the heart and thymus gland. Vishudhi chakra related to respiration, (cervical plexus) is situated at the throat level below the larynx and regulates the functions of the thyroid gland and lungs.
Ajna chakra regulate the various physiological function (cervical plexus or optic chiasma) is situated between the eye brows and regulates the functions of pituitary gland. Sahasrara chakra (choroid plexus) is the limbic system of the brain, which consists of seven nerve nuclei which contains and integrates the control centers of the other six chakras. Practice of asanas and pranayama alert these centers. Kundalini shakti (serpentine power) normally remains dormant most of the time at the lowest chakra (mooladhara) as a potential energy, Just like a serpent remaining in a quiet and coiled state. This flow of energy activates the parasympathetic nervous system in the human body, which in turn relaxes body functions of the practitioner. It also gently nurtures and strengthen the limbic system, the emotional and motivational centre of the brain, which again relaxes the brain by regulating the thinking process. Such activation of parasympathetic-limbic pathway is the underlying neuro-physiological changes relaxes body and mind in yoga practice. Physical damage to one of these chakras can have an effect on the controlling centre of that chakra in the brain leading to concomitant psychological effects. These psychological problems can lead to psychosomatic disorders.

Many studies suggested that significant increases in cerebral blood flow in the human brain cingulate gyrus, inferior and orbital cortex, dorsolateral prefrontal cortex and thalamic regions, after one hour of meditation reflecting focused concentration and overall increased cortical activity during meditation $[1,2]$. Magnetic resonance imaging (MRI) also showed significant increases in various activation of neural structures involved in attention and control of the autonomic nervous system [3]. Visual analysis also showed more alpha EEG activity during meditation $(\mathrm{M}=1.71$ micro $\mathrm{V})$ compared to the pre- $(\mathrm{M}=0.47$ micro $\mathrm{V})$ and postbaseline ( $M=0.26$ micro $V$ ), and an increase in theta EEG activity immediately following the meditation [4].

A shift in breathing pattern during meditation may contribute to the development of more alpha EEG [5]. These findings suggest that meditation is a conscious mental process 
that induces a set of integrated physiological changes termed the relaxation response. Presence of more alpha waves also suggests good homogenicity, uniformity and increased orderliness of brain in meditators. Many evidence supports the belief that certain yoga techniques may improve physical and mental health and wellbeing through down-regulation of the hypothalamicpituitary-adrenal (HPA) axis and the sympathetic nervous system (SNS) in the human body, that started as a response to a physical or psychological demand (stressor), leading to a cascade of physiological, behavioral, and psychological effects in the body, primarily as a result of the secretions of cortisol and catecholamines (epinephrine and norepinephrine) [6].

This response leads to the mobilization of energy needed to fight by the stressor through the classic fight-or-flight response. Over time, the constant state of hyper vigilance resulting from repeated firing of the HPA axis and SNS can lead to dys-regulation of the system, and lead to various diseases such as obesity, diabetes, autoimmune disorders, depression, substance abuse, and cardiovascular disease [7]. Studies also show that yoga decreases the levels of salivary cortisol, blood glucose, as well as plasma renin levels, and 24-hour urine nor epinephrine and epinephrine levels. Yoga significantly decreases heart rate and systolic and diastolic blood pressure. Studies suggest that yoga prevent the negative effect of stress on the immune system of the human body by increasing levels of immunoglobulin A as well as natural killer cells. Yoga has been found to beneficial in decreasing the markers of inflammation such as high sensitivity C-reactive protein as well as inflammatory cytokines such as interleukin-6 and lymphocyte-1B [8]. These studies suggest that yoga has an immediate good effect on the SNS-HPA axis response to stress. While the precise mechanism of action has not been determined, it has been hypothesized that some yoga exercises cause a shift toward parasympathetic nervous system dominance, possibly via direct vagal stimulation. Shapiro et al noted significant reductions in low-frequency heart rate variability (HRV) a sign of sympathetic nervous system activation in depressed patients following an 8-week yoga intervention. Regardless of the pathophysiologic pathway, yoga has been shown to have immediate psychological effects: decreasing anxiety and increasing feelings of emotional, social, and spiritual well-being. Several authors and literature reviews have been conducted that examined the impact of yoga on specific health conditions, including cardiovascular disease, metabolic syndrome, diabetes, cancer, and anxiety [9].

Reibel et al. [9] conducted the study in 2001 which examined the effects of mindfulness-based stress reduction (MBSR) on health-related quality of life and physical and psychological symptomatology in a heterogeneous group of patient population. In the study patients participated in an 8 week MBSR program and were required to practice 20 minutes of meditation daily during intervention. Pre- and post-intervention data were collected and compared, and after a one-year follow-up, revealed maintenance of initial improvements on several outcome parameters. The author concluded that a group mindfulness meditation training program can enhance functional status and well-being, and reduce physical symptoms and psychological distress in a heterogeneous patient population, and that the intervention may have long-term beneficial effects [9].

Another study conducted by Campbell et al. [10], researchers at Deakin University in Melbourne, Australia, with the dual aims of better understanding the contribution of yoga to positive mental health and exploring links between yogic philosophy and psychological theory, conducted a study on yoga as a preventative and treatment for symptoms of mental illness. The yoga classes were designed for the six-week, various yoga technique incorporated such as breathing techniques (pranayama); exercises for strength, vitality, and flexibility (asanas); guided relaxation (yoga-nidra); and meditation. Psychometric testing was used to assess symptoms of stress, anxiety, and depression across three groups: regular yoga practitioners, beginners entering the program, and people who did not practice yoga. These tests were re-administered after six weeks, and the yoga beginners group showed lower average levels of symptoms of depression, anxiety, and stress than at commencement, but levels were stable for regular yoga practitioners and people who did not practice yoga [10].

Another study conducted by Parshad [11] about role of Yoga in stress management published in West Indies Med J, the author reported state of the mind and body are intimately related. If the mind is relaxed, the muscles in the body will also be relaxed. Stress produces a state of physical and mental tension in the human being. Yoga, developed thousands of years ago, is recognized as a form of mind-body medicine. In yoga, all aspects of wellbeing was taken care such as physical postures and breathing exercises improve muscle strength, flexibility, blood circulation and oxygen uptake as well as hormone function. In addition, the relaxation induced by meditation helps to stabilize the autonomic nervous system with a tendency towards parasympathetic dominance. Other than physiological benefits, yoga helps to the person become more resilient to stressful conditions and reduce a variety of important risk factors for various diseases, especially cardio-respiratory diseases [11].

\section{References}

1. Jevning R, Anand R, Biedebach M, Fernando G (1996) Effects on regional cerebral blood flow of transcendental meditation. Physiol Behavior 59(3): 399-402.

2. Newberg A, Alavi A, Baime M, Pourdehnad, Santanna J, et al. (2001) The measurement of the regional cerebral blood flow during the complex cognitive task of meditation: A preliminary SPECT study. Psychiatry Res 106(2): 113-122.

3. Lazar SW, Bush G, Gollub RL, Fricchione GL, Khalsa G, et al. (2000) Functional brain mapping of the relaxation response and meditation. Neuroreport 11(7): 1581-1585.

4. Khare KC, Nigam SK (2000) A study of electroencephalogram in meditators. Indian J Physiol Pharmacol 44(2): 173-178. 
5. Arambula P, Peper E, Kawakami M, Gibney KH (2001) The physiological correlates of kundalini yoga meditation: a study of yoga master. Appl Psychophysiol Biofeedback 26(2): 147-153.

6. Amber W Li, Golsmith CA (2011) The effects of yoga on anxiety and stress. Altern Med Revi 17(1): 21-35.

7. Gururaja D, Harano K, Toyotake I, Kobayashi H (2011) Effect of yoga on mental health: Comparative study between young and senior subjects in Japan. Int J Yoga 4(1): 7-12.

8. Caroline S, Heather H, Jane, Kerena EA (2007) Randomised comparative trial of yoga and relaxation to reduce stress and anxiety. Complementary Therapies in Medicine 15(2): 77-83.
9. Reibel DK, Greeson JM, Brainard GC, Rosenzweig S (2001) Mindfulness-based stress reduction and health-related quality of life in a heterogeneous patient population. General Hospital Psychiatry 23(4): 183-192.

10. Campbell, Debra E, Kathleen AM (2004) Yoga as a preventative and treatment for depression, anxiety, and stress. International Journal of Yoga Therapy 14: 53-58.

11. Parshad 0 (2004) Role of yoga in stress management. West Indian Med J 53(3): 191-194.

\section{Your next submission with Juniper Publishers} will reach you the below assets

- Quality Editorial service

- Swift Peer Review

- Reprints availability

- E-prints Service

- Manuscript Podcast for convenient understanding

- Global attainment for your research

- Manuscript accessibility in different formats

( Pdf, E-pub, Full Text, Audio)

- Unceasing customer service

Track the below URL for one-step submission https://juniperpublishers.com/online-submission.php 